Article

\title{
Comparison of Different GPP Models in China Using MODIS Image and ChinaFLUX Data
}

\author{
Zhengjia Liu ${ }^{1,2, *, \dagger}$, Lunche Wang ${ }^{3, \dagger}$ and Sisi Wang ${ }^{1,2}$
}

1 Key Laboratory of Land Surface Pattern and Simulation, Institute of Geographic Sciences and Natural Resources Research, Chinese Academy of Sciences, Beijing 100101, China;

E-Mail: wangss.13b@igsnrr.ac.cn

2 University of Chinese Academy of Sciences, Beijing 100049, China

3 State Key Laboratory of Information Engineering in Surveying, Mapping, and Remote Sensing, Wuhan University, Wuhan 430079, China; E-Mail: lunchewang@whu.edu.cn

$\dagger$ These authors contributed equally to this work.

* Author to whom correspondence should be addressed; E-Mail: liuzj.12b@igsnrr.ac.cn; Tel./Fax: +86-10-6488-9021.

External Editors: Gabriel Senay and Prasad S. Thenkabail

Received: 22 July 2014; in revised form: 20 October 2014/ Accepted: 21 October 2014 /

Published: 23 October 2014

\begin{abstract}
Accurate quantification of gross primary production (GPP) at regional and global scales is essential for carbon budgets and climate change studies. Five models, the vegetation photosynthesis model (VPM), the temperature and greenness model (TG), the alpine vegetation model (AVM), the greenness and radiation model (GR), and the MOD17 algorithm, were tested and calibrated at eight sites in China during 2003-2005. Results indicate that the first four models provide more reliable GPP estimation than MOD17 products/algorithm, although MODIS GPP products show better performance in grasslands, croplands, and mixed forest (MF). VPM and AVM produce better estimates in forest sites $\left(\mathrm{R}^{2}=0.68\right.$ and 0.67 , respectively); AVM and TG models show satisfactory GPP estimates for grasslands $\left(\mathrm{R}^{2}=0.91\right.$ and 0.9 , respectively). In general, the VPM model is the most suitable model for GPP estimation for all kinds of land cover types in China, with $\mathrm{R}^{2}$ higher than 0.34 and root mean square error (RMSE) lower than $48.79 \%$. The relationships between eddy $\mathrm{CO}_{2}$ flux and model parameters (Enhanced Vegetation Index (EVI), photosynthetically active radiation (PAR), land surface temperature (LST), air temperature, and Land Surface Water Index (LSWI)) are further analyzed to investigate the model's
\end{abstract}


application to various land cover types, which will be of great importance for studying the effects of climatic factors on ecosystem performances.

Keywords: gross primary production (GPP); MODIS; eddy covariance; model comparison; ChinaFLUX; land cover types

\section{Introduction}

Gross primary production (GPP), defined as the total amount of carbon dioxide fixed by plants in photosynthesis, is the first step in the input of atmospheric $\mathrm{CO}_{2}$ to terrestrial ecosystems [1-3]. GPP is a key component of the carbon biogeochemical cycle that links atmospheric $\mathrm{CO}_{2}$ and terrestrial ecosystems. Therefore, accurate and synoptic GPP quantification at regional and global scales can improve our understanding about the mechanisms of carbon budgets and global climate change.

The eddy covariance (EC) technique measures net $\mathrm{CO}_{2}$ exchange, which can provide valuable information for developing and validating GPP models at ecosystem scale [4,5]. Satellite remote sensing can provide continuous, repetitive, and consistent observations of dynamic changes in terrestrial ecosystem structure and function over large areas; it has become a more and more important tool for monitoring land surface properties. A number of remote sensing-based GPP models have been proposed, including the MOD17 algorithm [6], the vegetation photosynthesis model (VPM) [7], the temperature and greenness (TG) model [8], the physiological principles for predicting growth (3-PG) [9] model, the eddy covariance light use efficiency model (EC-LUE) [10], the vegetation index (VI) model [11], the alpine vegetation model (AVM) [12], and the greenness and radiation model (GR) $[13,14]$, etc. These GPP models can be generally classified into two categories. The first category includes models that employ the maximum light use efficiency (LUE)_VPM, MOD17, and EC-LUE - which require many ground meteorological observations (and LOOKUP tables based on vegetation types) as input variables. The demand of these variables is a bottleneck for the model application. The second category of GPP models, such as TG, VI, and GR, are those entirely based on the relationships between remote sensing data and key factors affecting photosynthesis. Though the second category of models reduces or avoids dependence on ground meteorological observations, the ecological meaning of the model parameters is not so clear; model results may not be as good as with the first category. Substantial variations and uncertainties exist in the GPP estimations from different models. Therefore, it is essential to analyze the dependence of GPP models on climate variables and compare the model performances in different eco-regions with diverse canopy structures and climate characteristics.

Though there are lots of studies focusing on GPP estimations in China using different models - for example, Li et al. [15] estimated GPP in the Tibetan Plateau using MODIS images and climate data; Li et al. [12] estimated GPP of alpine grasslands using AVM model; and Gao et al. [5] reported a MODIS-based Photosynthetic Capacity Model to estimate GPP in Northern China and the Tibetan Plateau - there are very few studies focusing on comparing and evaluating these models in different land cover types in China. The most suitable GPP models should be chosen and calibrated for application in different ecosystems. 
In this paper, five GPP models, i.e., the VPM, TG, AVM, GR, and MODIS GPP algorithm (MOD_ALG), will be tested and calibrated at five land cover types (eight sites) in China using MODIS image, climate variables, and $\mathrm{CO}_{2}$ flux measurements during 2003-2005. The objectives of this study are: (1) to calibrate different GPP models in different eco-regions in China; (2) to apply the ground flux measured data and MOD17 to give a full evaluation of different GPP models; and (3) to compare the model accuracies and examine the parameters (key control factors) and sensitivities during photosynthesis. These analyses will improve quantification of the temporal changes in GPP in typical ecosystems in China.

\section{Data and Methods}

\subsection{Study Sites and Flux Measurements}

The carbon flux observed data (net ecosystem exchange (NEE) and ecosystem respiration (Re)) and meteorological data (air temperature and photosynthetically active radiation (PAR)) for 2003-2005 were downloaded from the ChinaFLUX website $[4,16]$. The measured GPP $\left(\mathrm{gC} / \mathrm{m}^{2} / \mathrm{d}\right)$ was then given by subtracting Re from NEE as: GPP $=$ NEE - Re. The daily data were integrated based on the filled half-hourly values $[4,16]$. More information about original observed half-hour values can be found at $\mathrm{Yu}$ et al. [4] and Gao et al. [5]. Finally, eight-day flux observed data from calculations of daily data were used for calibrating and validating GPP models. In this study, eight sites in five different land cover types were used: croplands (YuCheng (YC) in Shandong province), grasslands (XiLinGuoLe (XLGL) in Inner Mongolia autonomous region, HaiBei (HB) in Qinghai province, and DangXiong (DX) in Tibet autonomous region), mixed forests (ChangBaiShan (CBS) in Jilin province), evergreen needleleaf forests (QianYanZhou (QYZ) in Jiangxi province), and evergreen broadleaf forests (DingHuShan (DHS) in Guangdong province and XiShuangBanNa (XSBN) in Yunnan province). A brief description of these sites is presented in Table 1 and Figure 1. All effective measurements were divided into two groups: one for model calibration, including $70 \%$ of all the data (randomly chosen), and the remainder for validation.

Table 1. A brief description of eight flux sites in this study.

\begin{tabular}{ccccc}
\hline Sites ID & Lat $\left({ }^{\circ} \mathbf{N}\right)$ & Lon $\left({ }^{\circ} \mathbf{E}\right)$ & Data Range & Land Cover \\
\hline CBS & 42.40 & 128.10 & $2003-2005$ & MF \\
DHS & 23.17 & 112.53 & $2003-2005$ & EBF \\
QYZ & 26.75 & 115.67 & $2003-2005$ & ENF \\
XSBN & 21.90 & 101.27 & $2003-2005$ & EBF \\
YC & 36.95 & 116.6 & $2003-2005$ & Croplands \\
HB & 37.62 & 101.32 & $2003-2005$ & Grasslands \\
XLGL & 43.63 & 116.70 & $2003-2004$ & Grasslands \\
DX & 30.83 & 91.12 & $2003-2004$ & Grasslands \\
\hline
\end{tabular}


Figure 1. Spatial distributions of eight flux sites in this study. EBF: evergreen broadleaf forests; ENF: evergreen needleleaf forests; MF: mixed forests.

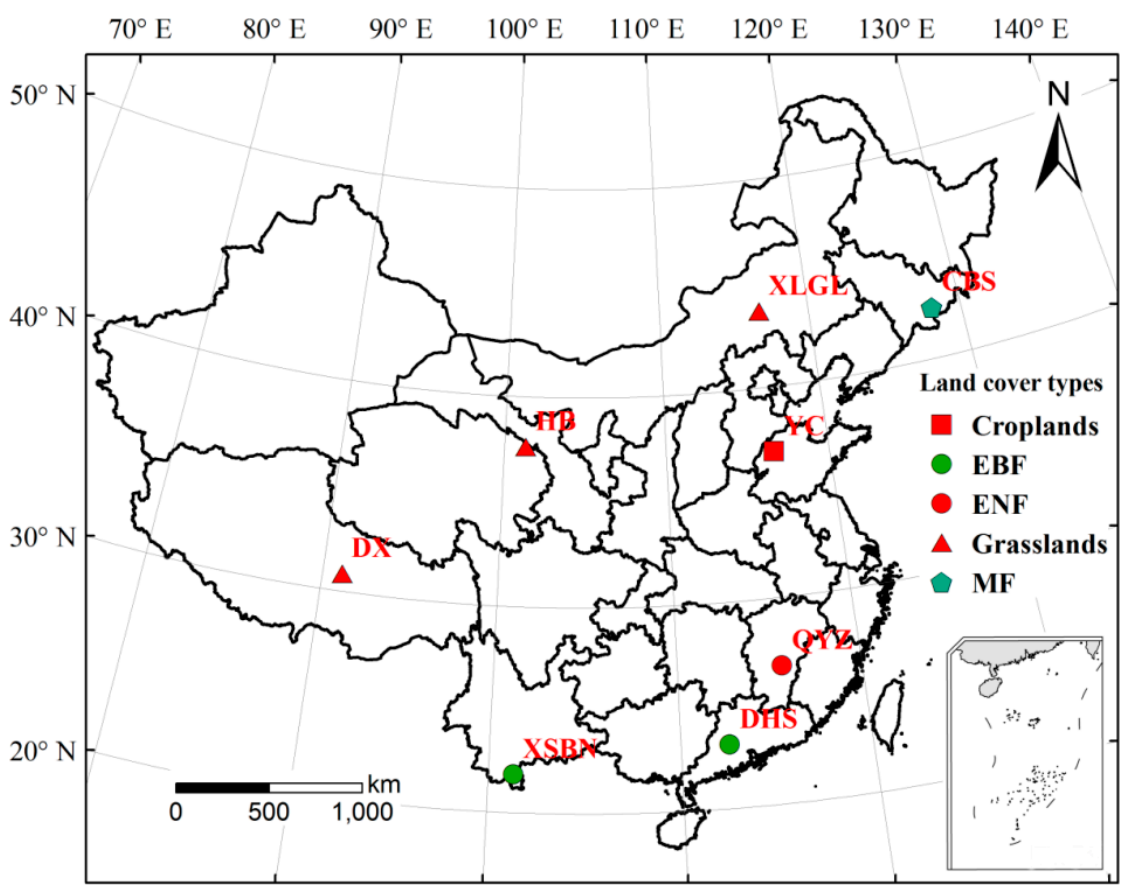

\subsection{MODIS Data}

In order to test and validate GPP models at the flux sites, MODIS products (collection 5, including eight-day surface reflectance MOD09A1, eight-day MOD17, and eight-day land surface temperature (LST) product) in the period of 2003-2005 were downloaded [17]. MOD17 values were calculated using the following algorithm:

$$
\mathrm{GPP}=\varepsilon_{\max } \times \mathrm{f}\left(\mathrm{T}_{\min }\right) \times \mathrm{f}(\mathrm{VPD}) \times \mathrm{FPAR} \times \mathrm{SW}_{\text {rad }} \times 0.45
$$

where $\varepsilon_{\max }$ is the maximum LUE obtained from LOOKUP table on the basis of vegetation type [17]. The attenuation scalars $f\left(T_{\min }\right)$ and $f(V P D)$ are simple linear regression functions of daily minimum temperature $\left(\mathrm{T}_{\min }\right)$ and vapor pressure deficit $(\mathrm{VPD})$, and values of $\mathrm{T}_{\min }, \mathrm{VPD}$ and $\mathrm{SW}$ rad were obtained from the Date Assimilation Office (DAO) dataset [6,17]. MOD09A1 (500 m spatial resolution) was calculated from MODIS level 1B, which provides seven spectral bands: red (620-670 nm), $\mathrm{NIR}_{1} \quad(841-876 \mathrm{~nm})$, blue $(459-479 \mathrm{~nm})$, green $(545-565 \mathrm{~nm})$, NIR 2 (1230-1250 nm), SWIR $_{1}(1628-1652 \mathrm{~nm})$, and SWIR $2(2105-2155 \mathrm{~nm})$ [18]. Based on MOD09A1, we computed the Land Surface Water Index (LSWI) [19] and Enhanced Vegetation Index (EVI) [20], respectively.

$$
\begin{gathered}
\mathrm{LSWI}=\frac{\mathrm{NIR}_{1}-\mathrm{SWIR}_{1}}{\mathrm{NIR}_{1}+\mathrm{SWIR}_{1}} \\
\mathrm{EVI}=\frac{\mathrm{NIR}_{1}-\text { red }}{\mathrm{NIR}_{1}+6 \times \text { red }-7.5 \times \text { blue }+1}
\end{gathered}
$$

The S-G filter was used to smooth the noise of remote sensing data induced by cloudy and atmospheric contaminations [21]. Based on latitude and longitude information of eight flux sites, MOD17, LST, EVI, and LSWI at eight-day composites were finally extracted from $3 \times 3 \mathrm{~km}(3 \times 3$ 
pixels for $1 \mathrm{~km}$ spatial resolution data and $6 \times 6$ pixels for $500 \mathrm{~m}$ spatial resolution data) around the center of flux towers $[11,22,23]$.

\subsection{Model Descriptions}

\subsubsection{The AVM}

The AVM model developed by Li et al. [12] is based on the EVI and air temperature. An important finding is that daily variance of GPP in alpine meadows during the growing season can be expressed in terms of EVI and air temperature. AVM has only been tested in alpine grasslands and the model calibration in the other ecosystems is still unknown. The AVM is expressed as:

$$
\mathrm{GPP}=\mathrm{m} \times \mathrm{EVI}_{\text {scaled }} \times \mathrm{T}_{\text {scaled }}
$$

where $m$ is a conversion coefficient with the unit of $\mathrm{gC} / \mathrm{m}^{2} /$ eight-day, and $\mathrm{EVI}_{\text {scaled }}$ is given by:

$$
\mathrm{EVI}_{\text {scaled }}=\mathrm{EVI}-\mathrm{EVI}_{\text {base }}
$$

where $\mathrm{EVI}_{\text {base }}$ is set to be 0.15 [12]. When EVI is less than $\mathrm{EVI}_{\text {base }}, \mathrm{EVI}_{\text {scaled }}$ is set as $0 . \mathrm{T}_{\text {scaled }}$ is the air temperature stress factor:

$$
\mathrm{T}_{\text {scaled }}=\left(\mathrm{T}_{\mathrm{a}}-\mathrm{T}_{\min }\right) /\left(\mathrm{T}_{\max }-\mathrm{T}_{\min }\right)
$$

where $T_{a}$ is the mean air temperature for each eight-day period; $T_{\min }$ and $T_{\max }$ are the biological minimum and maximum temperature during the growing season, respectively (Table 2). If $\mathrm{T}_{\mathrm{a}}$ is less than $\mathrm{T}_{\min }, \mathrm{T}_{\text {scaled }}$ is set as 0 .

\subsubsection{The GR Model}

The GR model introduced by Gitelson et al. [13] has shown high potential for estimating GPP in croplands. Wu et al. [24] calibrates this model and successfully applies it to forest ecosystems. The GR model can be scaled up using a remote sensing vegetation index as a proxy for the total chlorophyll content:

$$
\mathrm{GPP}=\mathrm{m} \times \mathrm{VI} \times \mathrm{PAR}
$$

In this study, $m$ is an empirical coefficient with the unit of $\mathrm{gC} / \mathrm{MJ} /$ eight-day, and VI is EVI. The incoming PAR is acquired from the meteorological observations.

\subsubsection{The TG Model}

The TG model, developed by Sims et al. [8], estimates vegetation GPP using MODIS, LST, and EVI products. An important merit of this model is the independence of climate variables. GPP is estimated as a product of the scaled EVI and scaled LST:

$$
\mathrm{GPP}=\mathrm{m} \times \mathrm{EVI}_{\text {scaled }} \times \mathrm{LST}_{\text {scaled }}
$$

here, $m$ is a scalar with the unit of $\mathrm{gC} / \mathrm{m}^{2} /$ eight-day, and $\mathrm{EVI}_{\text {scaled }}$ has a function similar to that of the AVM, but $\mathrm{EVI}_{\text {base }}$ is set to be $0.1[8,11]$. 
The $\mathrm{LST}_{\text {scaled }}$ is based on the determination of optimum temperature for GPP. GPP presents a maximum value for the $\mathrm{LST}_{\text {scaled }}$ of 1.0 when LST is equal to $30{ }^{\circ} \mathrm{C}$ and a minimum value of 0 when LST declines to $0{ }^{\circ} \mathrm{C}$ or increases to $50{ }^{\circ} \mathrm{C}$.

$$
\mathrm{LST}_{\text {scaled }}=\min \left[\left(\frac{\mathrm{LST}}{30}\right) ;(2.5-0.05 \times \mathrm{LST})\right]
$$

\subsubsection{The VPM}

The VPM assumes that leaves and plant canopies are composed of photosynthetically active vegetation (PAV, mostly chloroplast) and non-photosynthetic vegetation (NPV, mostly senescent foliage, branches, and stems) [7]. Based on the conceptual partitioning of PAV and NPV within the canopies, the VPM was built as follows:

$$
\mathrm{GPP}=\varepsilon \times \mathrm{FPAR} \times \mathrm{PAR}
$$

where FPAR is the fraction of PAR absorbed by the plant canopy, the product of FPAR and PAR is the PAR absorbed by the plant canopy (APAR), and $\varepsilon$ is the LUE.

The VPM acquires biome-specific $\varepsilon_{\max }$ from the literature or from the relationship between NEE and incident PAR; the temperature and water stress are chosen to down-regulate $\varepsilon_{\max }$. Thus, in the $\mathrm{VPM}, \varepsilon$ is described as:

$$
\varepsilon=\varepsilon_{\text {max }} \times \mathrm{T}_{\text {scaled }} \times \mathrm{W}_{\text {scaled }} \times \mathrm{P}_{\text {scaled }},
$$

where $\varepsilon_{\max }$ is the maximum LUE; and $\mathrm{T}_{\text {scaled }}, \mathrm{W}_{\text {scaled, }}$ and $\mathrm{P}_{\text {scaled }}$ are the down-regulation scalars for the efficiency of temperature, water, and leaf phenology on the $\varepsilon_{\max }$, respectively.

$$
\mathrm{T}_{\text {scaled }}=\frac{\left(\mathrm{T}_{\mathrm{a}}-\mathrm{T}_{\min }\right) \times\left(\mathrm{T}_{\mathrm{a}}-\mathrm{T}_{\max }\right)}{\left(\mathrm{T}_{\mathrm{a}}-\mathrm{T}_{\min }\right) \times\left(\mathrm{T}_{\mathrm{a}}-\mathrm{T}_{\max }\right)-\left(\mathrm{T}_{\mathrm{a}}-\mathrm{T}_{\mathrm{opt}}\right)^{2}}
$$

here, $\mathrm{T}_{\mathrm{a}}$ is the mean temperature for each of the eight days; $\mathrm{T}_{\min }, \mathrm{T}_{\max }$, and $\mathrm{T}_{\mathrm{opt}}$ are the minimum, maximum, and optimal air temperature for photosynthetic activities, respectively. If $\mathrm{T}_{\mathrm{a}}$ falls below $\mathrm{T}_{\min }, \mathrm{T}_{\text {scaled }}$ is set as 0 . In this study, the values of $\mathrm{T}_{\min }, \mathrm{T}_{\max }$, and $\mathrm{T}_{\text {opt }}$ can be seen in Table 2 .

$$
\mathrm{W}_{\text {scaled }}=\frac{1+\mathrm{LSWI}}{1+\mathrm{LSWI}_{\max }}
$$

here, $\mathrm{LSWI}_{\max }$ is the maximum LSWI within the growing season.

Calculation of FPAR depends upon a linear relationship with EVI. It is also a challenging variable in the VPM.

$$
\operatorname{FPAR}=\alpha \times \mathrm{EVI}
$$

generally, the coefficient $\alpha$ is set to be 1.0 [7].

$$
\mathrm{P}_{\text {scaled }}=\frac{1+\mathrm{LSWI}}{2}
$$

during bud burst to leaf full expansion; $\mathrm{P}_{\text {scaled }}=1$, after full leaf expansion. 
Table 2. Models' temperature parameters in different land cover types. $T_{\min }, \mathrm{T}_{\max }$, and $\mathrm{T}_{\mathrm{opt}}$ are the biological minimum temperature, maximum temperature, and optimal temperature during the growing season.

\begin{tabular}{cccc}
\hline & $\mathbf{T}_{\min }\left({ }^{\circ} \mathbf{C}\right)[\mathbf{8}]$ & $\mathbf{T}_{\mathbf{m a x}}\left({ }^{\circ} \mathbf{C}\right)[\mathbf{8}]$ & $\mathbf{T}_{\text {opt }}\left({ }^{\circ} \mathbf{C}\right)[\mathbf{2 5}]$ \\
\hline CBS & 0.0 & 50.0 & 20.7 \\
DHS & 0.0 & 50.0 & 23.4 \\
QYZ & 0.0 & 50.0 & 22.4 \\
XSBN & 0.0 & 50.0 & 23.4 \\
YC & 0.0 & 50.0 & 24.8 \\
HB & 0.0 & 50.0 & 15.4 \\
XLGL & 0.0 & 50.0 & 15.4 \\
DX & 0.0 & 50.0 & 15.4 \\
\hline
\end{tabular}

\subsection{Analyses}

Statistic indices, including coefficient of determination $\left(\mathrm{R}^{2}\right)$, root mean square error (RMSE) as a percentage of the mean value $(\operatorname{RMSE}(\%))$, and bias (the difference between simulations and observations), were employed to evaluate the model performances.

$$
\text { RMSE }=\frac{100}{\bar{X}_{\text {obs }}} \times \sqrt{\frac{1}{n} \times \sum_{i=1}^{n}\left(X_{\text {sim_i }_{i}}-X_{o b s_{-} i}\right)^{2}}
$$

here, $\bar{X}_{o b s}$ is the average of the observed values; $\mathrm{X}_{\text {sim_i }_{-}}$and $\mathrm{X}_{\mathrm{obs} \_\mathrm{i}}$ are the $i$ th simulated and observed values, respectively; and $n$ is the total number of samples.

\section{Results}

\subsection{MOD17 Validations}

In this study, we first compared the MOD17 with the measured GPP (GPP_EC) (Figure 2). The R ${ }^{2}$ equals 0.58 and RMSE equals $67.19 \%$ for the overall data between the GPP_EC and MOD17. For the five land cover types, MOD17 for grasslands generally shows a better correlation with GPP_EC, with $\mathrm{R}^{2}$ being 0.90 . MOD17 for croplands and MF also show relative high correlations with the measured fluxes ( $\mathrm{R}^{2}$ are 0.8 and 0.76 , respectively); however, low correlations have also been found for ENF and EBF ( $\mathrm{R}^{2}$ are 0.44 and 0.21 , respectively). These differences may be due to the fact that the MOD17 algorithm generally has a good performance when the measured GPP value is relatively small (GPP_EC $<40 \mathrm{gC} / \mathrm{m}^{2} /$ eight-day or lower). With increasing GPP_EC values, MOD17 gets more dispersive, especially in ENF and EBF. Although a previous study indicated that the MODIS algorithm was poor at estimating GPP in MF or open scrubland [26], our results show that MODIS-GPP performed better in MF but worse in EBF and ENF. 
Figure 2. Relationship between the flux measured GPP (GPP_EC, X-axis) and results of MOD17 (Y-axis) for five different land cover types. The dashed line indicates 1:1 line. The red solid line indicates a linear trend for all types.

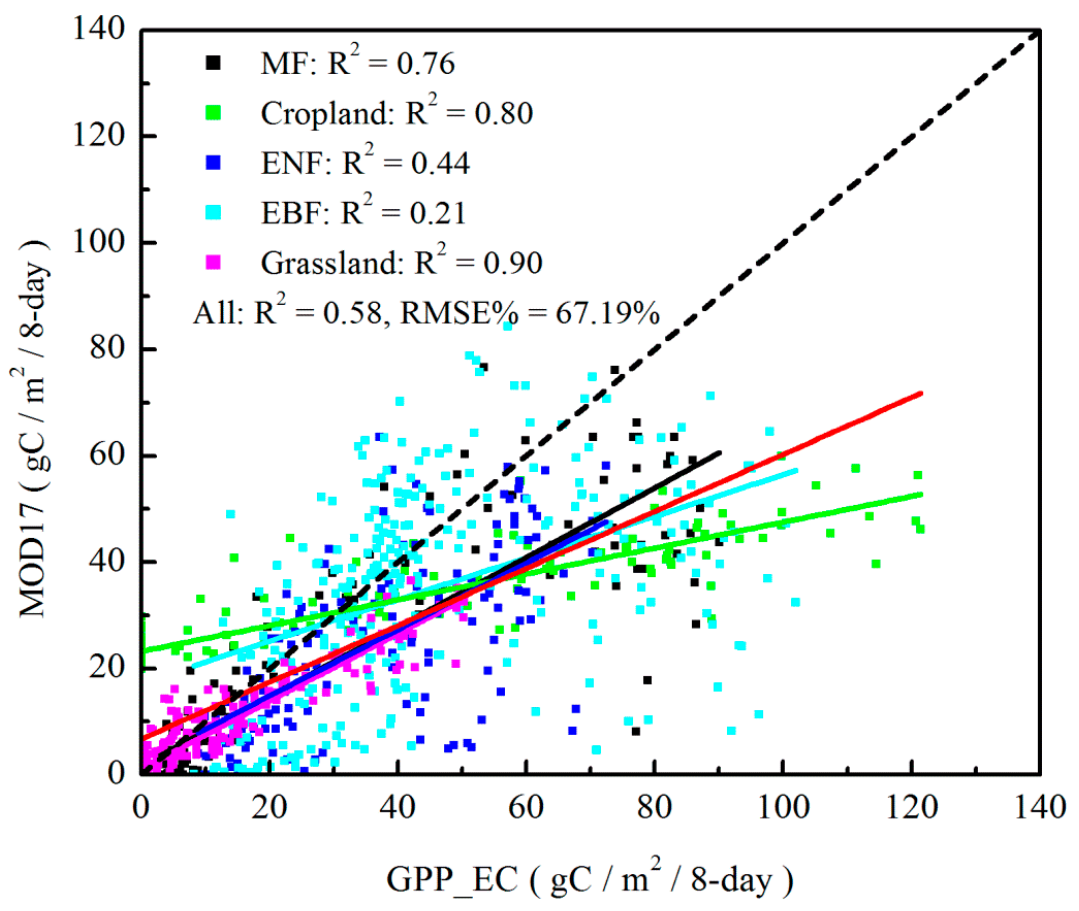

\subsection{Calibration and Validation for Each Model}

Table 3 shows the statistic summaries for the results of AVM, GR, TG VPM, and MOD_ALG at the periods of calibration and validation. Each model performs well at most sites in the period of calibration, indicating that these models have potential to capture the physical process of GPP variations. For AVM, $\mathrm{R}^{2}$ values range from 0.29 (EBF) to 0.97 (MF) during the model calibration; RMSE varies from $25.98 \%$ in MF to $67.78 \%$ for croplands. It was discovered that AVM slightly underestimates GPP_EC for each land cover type from $-0.64 \mathrm{gC} / \mathrm{m}^{2} /$ eight-day (grasslands) to $-16.78 \mathrm{gC} / \mathrm{m}^{2} /$ eight-day (EBF). At the same time, $\mathrm{R}^{2}$ values vary from 0.26 in $\mathrm{EBF}$ to 0.83 in grasslands; RMSE varies from $46.31 \%$ in ENF to $114.92 \%$ in grasslands for GR model. The GR model also slightly overestimates GPP_EC in MF, croplands and grasslands, and underestimates GPP_EC in evergreen forests. A similar phenomenon has also been found at AmeriFlux sites [27]. For the TG model, $\mathrm{R}^{2}$ values range from 0.36 in EBF to 0.94 in MF; RMSE ranges from $25.58 \%$ in MF to $59.69 \%$ in croplands. The TG model generally underestimates GPP_EC, except in grasslands. For VPM, ${ }^{2}$ values range from 0.36 in EBF to 0.89 in grasslands; RMSE ranges from $41.23 \%$ in MF to $59.80 \%$ in grasslands. The VPM underestimates GPP_EC in most land cover types except for grasslands. For MOD_ALG, $\mathrm{R}^{2}$ values vary from 0.17 in EBF to 0.89 in grasslands; RMSE varies from $51.81 \%$ in croplands to $77.42 \%$ in EBF. MOD_ALG usually underestimates GPP_EC, except in grasslands and croplands. Parameters of the amount of carbon fixed in photosynthesis $(\mathrm{m})$ or LUE $\left(\varepsilon_{\max }\right)$ in different models for each land cover type are shown in Table 4. In MOD17 LOOKUP table [17], the $\varepsilon_{\max }$ of MF, $\mathrm{ENF}$, and grasslands (5.44 $\mathrm{gC} / \mathrm{MJ} /$ eight-day, $8.06 \mathrm{gC} / \mathrm{MJ} /$ eight-day, and $5.44 \mathrm{gC} / \mathrm{MJ} /$ eight-day, respectively) are close to values of MOD_ALG, but the $\varepsilon_{\max }$ of croplands $(5.44 \mathrm{gC} / \mathrm{MJ} /$ eight-day) is 
lower than the value of MOD_ALG, and the $\varepsilon_{\max }$ of EBF $(9.27 \mathrm{gC} / \mathrm{MJ} /$ eight-day $)$ is lower than the value of MOD_ALG. The large variation of $\varepsilon_{\max }$ in EBF and croplands suggest that more calibrations of LUE are necessary.

In the process of model validation, the above five GPP models also perform well in most land cover types. $\mathrm{R}^{2}$ values are generally larger than those in model calibration, except in ENF and EBF; for example, $\mathrm{R}^{2}$ values are higher than 0.79 and 0.94 in $\mathrm{MF}$ and grasslands, respectively; $\mathrm{R}^{2}$ between measured and estimated GPP in croplands ranges from 0.76 for AVM to 0.91 for VPM. Interestingly, although GR, TG, and MOD_ALG do not show good performance in the model calibration for croplands, all three models show better results in the model validation. However, the validation performance in ENF is poorer than that in calibration. Extreme values existing in the periods of calibration and validation may explain the discrepancy. From the above analysis, we can conclude that the five models above can be used for GPP estimations in different ecosystems in China.

Table 3. Model performances at the periods of calibration and validation. Unit of bias: $\mathrm{gC} / \mathrm{m}^{2} /$ eight-day.

\begin{tabular}{|c|c|c|c|c|c|c|c|c|c|c|c|c|c|c|c|}
\hline \multirow[b]{2}{*}{ Model } & \multicolumn{3}{|c|}{ MF } & \multicolumn{3}{|c|}{ Croplands } & \multicolumn{3}{|c|}{ ENF } & \multicolumn{3}{|c|}{ EBF } & \multicolumn{3}{|c|}{ Grasslands } \\
\hline & Bias & $\mathrm{RMSE} \%$ & $\mathrm{R}^{2}$ & Bias & RMSE\% & $\mathrm{R}^{2}$ & Bias & RMSE\% & $\mathrm{R}^{2}$ & Bias & RMSE\% & $\mathrm{R}^{2}$ & Bias & RMSE\% & $\mathrm{R}^{2}$ \\
\hline & \multicolumn{15}{|c|}{ Calibration } \\
\hline AVM & -5.28 & 25.98 & 0.97 & -9.89 & 67.78 & 0.64 & -16.14 & 48.91 & 0.72 & -16.78 & 58.55 & 0.29 & -0.64 & 55.22 & 0.90 \\
\hline GR & 7.70 & 51.72 & 0.82 & 13.13 & 61.31 & 0.77 & -14.64 & 46.31 & 0.69 & -16.55 & 58.90 & 0.26 & 6.50 & 114.92 & 0.83 \\
\hline VPM & -5.30 & 41.23 & 0.87 & -1.06 & 45.48 & 0.81 & -16.29 & 48.52 & 0.75 & -14.23 & 53.40 & 0.36 & 1.19 & 59.80 & 0.89 \\
\hline \multirow[t]{2}{*}{ MOD_ALG } & -6.46 & 58.43 & 0.73 & 3.98 & 51.81 & 0.76 & -18.32 & 57.87 & 0.51 & -27.33 & 77.42 & 0.17 & 1.30 & 58.57 & 0.89 \\
\hline & \multicolumn{15}{|c|}{ Validation } \\
\hline AVM & -10.48 & 39.15 & 0.99 & -9.62 & 56.77 & 0.76 & -11.60 & 42.47 & 0.60 & -13.68 & 46.81 & 0.20 & 1.07 & 36.40 & 0.96 \\
\hline GR & 3.53 & 37.51 & 0.89 & 8.29 & 42.74 & 0.88 & -9.00 & 40.08 & 0.53 & -10.92 & 41.83 & 0.27 & 7.40 & 76.40 & 0.94 \\
\hline VPM & -8.97 & 40.16 & 0.94 & -4.35 & 34.15 & 0.91 & -11.51 & 42.94 & 0.60 & -8.24 & 36.49 & 0.38 & 2.86 & 42.11 & 0.96 \\
\hline MOD_ALG & -9.99 & 57.16 & 0.79 & 0.60 & 40.12 & 0.85 & -15.94 & 54.96 & 0.43 & -21.78 & 61.34 & 0.19 & 2.21 & 40.92 & 0.94 \\
\hline
\end{tabular}

Table 4. Parameters of light use efficiency (LUE) ( $\varepsilon_{\max }$ VPM and $\varepsilon_{\max }$ MOD_ALG) and the amount of carbon fixed in photosynthesis ( $m_{-}$GR, $m_{-}$AVM, and $m_{-}$TG) in different models for each land cover type.

\begin{tabular}{|c|c|c|c|c|c|}
\hline Land Cover Types & $\begin{array}{c}m_{-} \text {AVM } \\
\left(\mathrm{gC} / \mathrm{m}^{2} / \text { Eight-Day }\right)\end{array}$ & $\begin{array}{c}m_{-} \text {GR } \\
\text { (gC/MJ/Eight-Day) }\end{array}$ & $\begin{array}{c}m_{-} \text {TG } \\
\left(\mathrm{gC} / \mathrm{m}^{2} / \text { Eight-Day }\right)\end{array}$ & $\begin{array}{c}\varepsilon_{\text {max_VPM }} \\
\text { (gC/MJ/Eight-Day) }\end{array}$ & $\begin{array}{c}\varepsilon_{\mathrm{max}} \text { MOD_ALG } \\
\text { (gC/MJ/Eight-Day) }\end{array}$ \\
\hline MF & 255.34 & 11.39 & 123.90 & 11.11 & 9.32 \\
\hline Croplands & 325.65 & 20.85 & 171.92 & 23.74 & 17.66 \\
\hline ENF & 130.29 & 7.37 & 74.24 & 8.08 & 7.41 \\
\hline $\mathrm{EBF}$ & 130.16 & 7.65 & 87.57 & 9.59 & 5.03 \\
\hline Grasslands & 222.39 & 6.82 & 87.02 & 8.83 & 6.95 \\
\hline
\end{tabular}




\subsection{Comparison among Results from Different Models}

\subsubsection{Forest Sites}

In this study, AVM, GR, TG, and VPM generally provide better estimates than MOD17/MOD_ALG in different ecosystems, and the VPM and TG models produce the highest estimating accuracy (Table 5). Higher $\mathrm{R}^{2}$ values at MF for both models suggest that a combination of EVI and temperature can better capture the temporal change of GPP_EC, and the TG model produces lower RMSE and bias. Similar results have been reported by Wu et al. [11] for EBF sites: they used air temperature as a proxy of LST in the TG model and found that correlations were significantly improved. Because meteorological variables are not often available at the required temporal/spatial resolution, a TG model entirely based on remote sensing data shows great potential for estimating GPP at a regional or global scale. Meanwhile, the lower $\mathrm{R}^{2}$ values for all models in EBF suggest that this linear regression relationship may not be suitable for EBF sites.

Apart from EVI and temperature, water stress is another important environmental factor influencing the actual LUE under unfavorable conditions for ENF. AVM brings a good GPP estimation $\left(\mathrm{R}^{2}=0.67\right)$, and VPM produces a better estimation at ENF with $\mathrm{R}^{2}$ of 0.68 , which may be due to water stress. GR and TG models provide lower values of RMSE and bias, but $R^{2}(0.61)$ is obviously lower than those for AVM and VPM.

\subsubsection{Nonforest Sites}

Air temperature is not usually a limitation factor in temperate croplands for GPP estimations, so $\mathrm{R}^{2}$ values for AVM and TG models are lower than those for VPM, GR, and MOD_ALG. VPM gives the best performance $\left(\mathrm{R}^{2}=0.84\right.$ and $\left.\mathrm{RMSE}=42.24 \%\right)$, indicating that water may be another important influencing factor.

AVM and TG models show satisfactory GPP estimates for grasslands $\left(\mathrm{R}^{2}=0.91\right.$ and 0.9 , respectively); RMSE values from both models are lower than MOD17/MOD_ALG. Li et al. [12] reported that AVM may be the optimum model to reflect GPP estimates when compared with the other four models in grasslands. The GR model generally overestimates GPP values due to the lack of EVI $_{\text {based; }}$ VPM shows large uncertainty at higher GPP values. Therefore, EVI and temperature are more sensitive factors in GPP estimation in grasslands.

Table 5. Performance of AVM, GR, TG, VPM, MOD17, and MOD_ALG models over the study period. Unit of bias: $\mathrm{gC} / \mathrm{m}^{2} /$ eight-day.

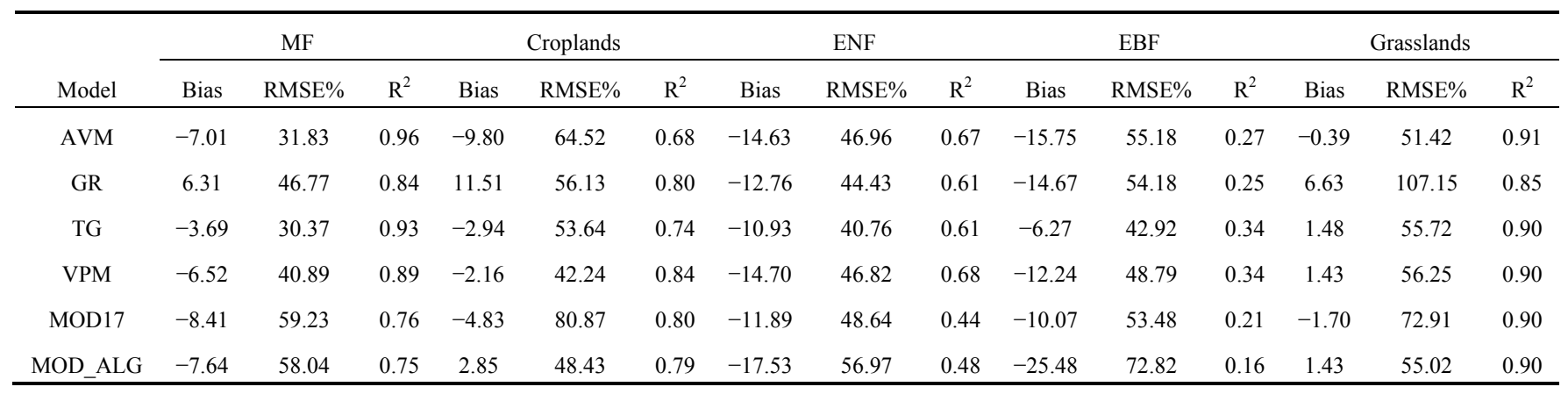




\subsection{Seasonal Variations of GPP for Each Site}

Figure 3 shows the seasonal variations of measured and estimated GPP using different models at eight sites in China during the study period. It is clear that GPP values generally increase from winter to summer; the averages of measured GPP in summer are 15.91, 75.89, 36.61, 55.95, 85.3, 66.09, 38.88 and $8.7 \mathrm{gC} / \mathrm{m}^{2}$ /eight-day for the XLGL, CBS, DHS, QYZ, XSBN, YC, HB, and DX sites, respectively. Different models play different roles in GPP estimation at each site (Figure 3); for example, all models (AVM, GR, TG, VPM, MOD17, and MOD_ALG) generally underestimated GPP values at XSBN during 2003-2005, while GR and TG models overestimated GPP values at the DX site. Large differences and uncertainties exist in the model performances at different sites in China, which will be discussed in detail in the next sections.

Figure 3. Seasonal variations of measured and estimated GPP for each site during the study period (2004-2005 for XLGL and DX; 2003-2005 for CBS, DHS, QYZ, XSBN, YC, and $\mathrm{HB})$.
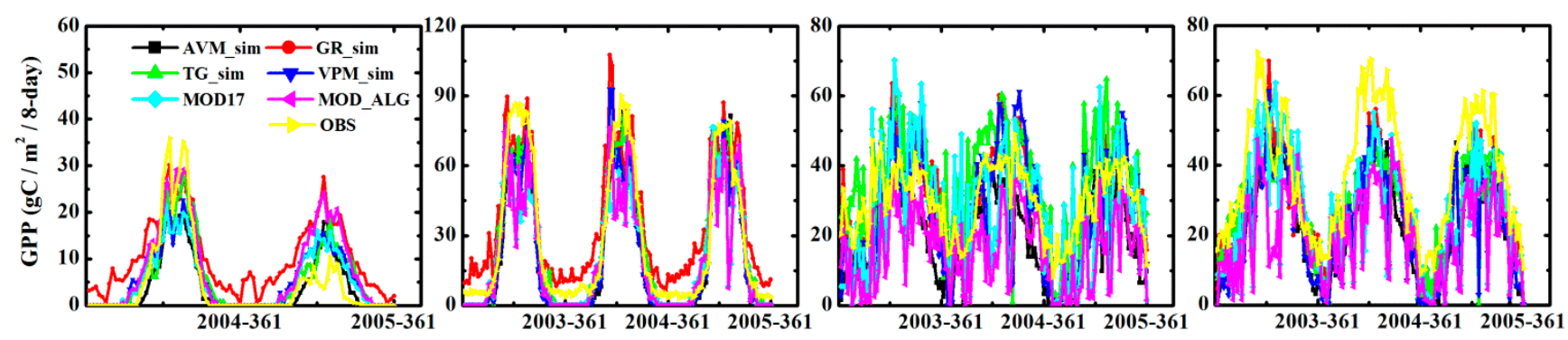

CBS

DHS

QYZ
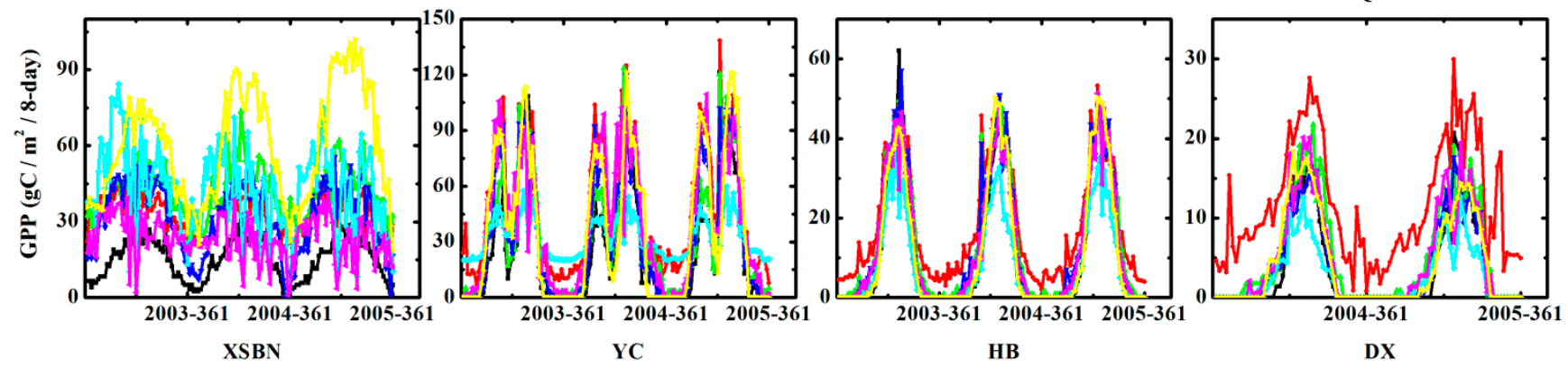

\section{Discussion}

In this paper, five models (AVM, GR, TG VPM, and MOD_ALG) are used for GPP estimation at different land cover types in China. The first four models provided better results than the MOD17/MOD_ALG; different models also showed different GPP results at different land cover types. In order to further analyze the model performances at various land cover types, the correlations between measured eddy $\mathrm{CO}_{2}$ flux data and main model parameters (EVI, PAR, LST, air temperature, and LSWI) are investigated in this section.

\subsection{Impact of EVI and PAR on Photosynthesis}

A typical difference among the GPP models is the use of EVI. For example, EVI (a measure of canopy greenness) is selected as a proxy of fraction of photosynthetically active radiation (FPAR) in 
the VPM and GR models for calculating photosynthetically active radiation absorbed (APAR) by the vegetation canopy. However, EVI is directly used as an indicator of greenness and canopy photosynthetic capacity [28,29], such as in the AVM and TG models.

We observe there is a good correlation between EVI and measured GPP; for example, the correlation coefficient $(\mathrm{r})$ values are $0.82,0.91$, and $0.95(\mathrm{P}<0.01)$ for croplands, grasslands, and $\mathrm{MF}$, respectively, so EVI can be used for estimating GPP at grasslands and MF sites with high accuracy. However, $r$ values between EVI and measured GPP at EBF and ENF are 0.41 and $0.55(\mathrm{P}<0.01)$, respectively. Thus, more environmental factors (PAR, temperature, and water stress) should be considered as conditions for GPP estimation. On the other hand, the differences in $r$ values for different land cover types suggest that EVI as a proxy of both LUE and FPAR is a good indicator for GPP estimation.

There is a significant positive correlation between EVI and PAR for most land cover types except grasslands, indicating that PAR can be obtained from EVI for describing canopy photosynthetic capacity. At the same time, the variation in $r$ value between PAR and measured GPP is higher than that between EVI and measured GPP at ENF sites, so a combination of PAR and EVI in the VPM model can produce a good estimation. As seen above, EVI can be a good indicator of GPP when there is a good correlation between EVI and GPP ( $r$ values $>0.9$ for grasslands and MF), and PAR is more important when the correlation is not so good (ENF sites).

\subsection{Impact of LST and Air Temperature on Photosynthesis}

Previous studies indicated that temperature (an external stress factor) directly affects the vegetation phenology, which played a significant role in carbon accumulation. It is observed that there is a good correlation between LST and air temperature at each site with different land cover types ( $\mathrm{r}>0.8$, $\mathrm{P}<0.01$ ). Most models used in this study (except GR) have considered the temperature effects, and the model performances indicate that temperature plays an important role in GPP estimations (Table 6). Meanwhile, it is discovered that using measured air temperature at the flux towers instead of LST can give a better GPP estimation for the TG model. Similar findings have also been reported by Wu et al. [11], as uncertainties in the satellite LST are excluded. Since MODIS LST provides a proxy of an average temperature across pixels, the TG model will be based entirely on remotely sensed variables without any ground meteorological input. According to the original TG model, LST is a useful measure of physiological activity in the top canopy leaves, which provide leaf cover great enough to avoid LST being significantly affected by soil surface temperature [8]. So the TG model shows a greater potential for GPP estimation in space.

Meanwhile, both LST and air temperature show good correlations with PAR $(r>0.5)$ at various land cover types, especially croplands, grasslands, and ENF sites, where $r$ values reach 0.7 , which indicates that temperature can provide the best estimation of PAR. Thus, the AVM and TG models can still produce satisfactory GPP estimates without considering the PAR in the model construction.

\subsection{Impact of Water Moisture on Photosynthesis}

As one of the external environmental factors, water stress has a significant impact on GPP estimations, especially during drought conditions. Our experiment shows that GPP is more sensitive to 
water stress at croplands and ENF sites $(r>0.6, P<0.01)$; the difference in $r$ value between LSWI and GPP_EC is 0.77, higher than 0.73 (air temperature vs. GPP_EC) or 0.69 (PAR vs. GPP_EC), indicating that more water is required for croplands.

Table 6. The correlation coefficient (r) values between various factors, including EVI, LST, LSWI, PAR, air temperature (Ta), and GPP_EC.

\begin{tabular}{|c|c|c|c|c|c|c|}
\hline & & LST & LSWI & PAR & $\mathbf{T a}$ & GPP_EC \\
\hline \multirow{6}{*}{ Croplands } & EVI & $0.52^{* *}$ & $0.81^{* *}$ & $0.46^{* *}$ & $0.67^{\text {** }}$ & $0.82^{* *}$ \\
\hline & LST & - & $0.30^{* *}$ & $0.25^{* *}$ & $0.96^{* *}$ & $0.64^{* *}$ \\
\hline & LSWI & - & - & $0.41^{* *}$ & $0.45^{* *}$ & $0.77^{* *}$ \\
\hline & PAR & - & - & - & $0.75^{* *}$ & $0.69^{* *}$ \\
\hline & $\mathrm{Ta}$ & - & - & - & - & $0.73^{* *}$ \\
\hline & GPP_EC & - & - & - & - & - \\
\hline \multirow{6}{*}{ EBF } & EVI & $0.23^{* *}$ & $0.50^{* *}$ & $0.34^{* *}$ & $0.28^{* *}$ & $0.41^{* *}$ \\
\hline & LST & - & 0.03 & $0.59^{* *}$ & $0.81^{* *}$ & $0.54^{* *}$ \\
\hline & LSWI & - & - & $0.21^{*}$ & $0.20^{* *}$ & $0.29^{* *}$ \\
\hline & PAR & - & - & - & $0.52^{* *}$ & $0.42^{* *}$ \\
\hline & $\mathrm{Ta}$ & - & - & - & - & $0.44^{* *}$ \\
\hline & GPP_EC & - & - & - & - & - \\
\hline \multirow{6}{*}{ ENF } & EVI & $0.52^{* *}$ & $0.41^{* *}$ & $0.57^{* *}$ & $0.57^{\text {** }}$ & $0.55^{* *}$ \\
\hline & LST & - & $0.50^{* *}$ & $0.77^{* *}$ & $0.92^{* *}$ & $0.80^{* *}$ \\
\hline & LSWI & - & - & $0.59^{* *}$ & $0.57^{* *}$ & $0.53^{* *}$ \\
\hline & PAR & - & - & - & $0.83^{* *}$ & $0.80^{* *}$ \\
\hline & $\mathrm{Ta}$ & - & - & - & - & $0.89^{* *}$ \\
\hline & GPP_EC & - & - & - & - & - \\
\hline \multirow{6}{*}{ Grasslands } & EVI & $0.46^{* *}$ & 0.09 & 0.10 & $0.69^{* *}$ & $0.91^{* *}$ \\
\hline & LST & - & $-0.61^{* *}$ & $0.66^{* *}$ & $0.90^{* *}$ & $0.44^{* *}$ \\
\hline & LSWI & - & - & $-0.28^{* *}$ & $-0.39^{* *}$ & $0.14^{* *}$ \\
\hline & PAR & - & - & - & $0.55^{* *}$ & $0.16^{* *}$ \\
\hline & $\mathrm{Ta}$ & - & - & - & - & $0.65^{* *}$ \\
\hline & GPP_EC & - & - & - & - & - \\
\hline \multirow{6}{*}{$\mathrm{MF}$} & EVI & $0.74^{* *}$ & $0.22^{* *}$ & $0.57^{* *}$ & $0.82^{* *}$ & $0.95^{* *}$ \\
\hline & LST & - & $-0.28^{* *}$ & $0.75^{* *}$ & $0.97^{* *}$ & $0.74^{* *}$ \\
\hline & LSWI & - & - & 0.03 & $-0.15^{* *}$ & $0.30^{* *}$ \\
\hline & PAR & - & - & - & $0.75^{* *}$ & $0.63^{* *}$ \\
\hline & $\mathrm{Ta}$ & - & - & - & - & $0.83^{* *}$ \\
\hline & GPP_EC & - & - & - & - & - \\
\hline
\end{tabular}

\subsection{Uncertainties, Errors, and Accuracies}

Generally, GPP_EC values are higher than MOD17 (Figure 2), which is consistent with Sims et al. [22] and Wu et al. [11]. It is reported that one significant limitation of the MOD17 algorithm is the improper characterization of LUE, so MOD17 is found to have underestimated peak values of GPP_EC $[11,22,30]$. In MOD17 and MOD_ALG, the same FPAR and different climate 
factors were used for estimating GPP. Table 3 and Table 5 show that MOD17 presents a comparable performance with MOD_ALG [6]. Through comparing flux measured climatic data with DAO data, Turner et al. [31] indicated that climatic data usually displayed good agreement for VPD and minimum temperature, but a high bias for DAO PAR. Therefore, we suggest that the uncertainty of climatic factors has little impact on MOD17. However, FPAR, as a key forcing variable of remote sensing, has a large uncertainty owing to the data qualities, thus it may be an important reason for underestimated peak values of GPP_EC [31-34]. Additionally, FPAR is derived from MODIS NDVI, which is sensitive to canopy background variations and saturates in areas with dense tree canopy, especially in the growing season $[35,36]$.

It is known that the above GPP models are highly dependent on each climatic factor, including minimum, maximum, and mean temperatures, water vapor, and PAR, which may majorly affect the model uncertainties, errors, and accuracies. In addition, remote sensing data is easily affected by cloudiness and aerosols; further work should be carried out to improve the data quality.

\section{Conclusions}

The eight-day GPP at eight sites with different land cover types in China during 2003-2005 was estimated from five models, namely the VPM, TG, AVM, GR, and MODIS GPP algorithm (MOD_ALG), using climate variables, flux observations, and MODIS images. The above five models were calibrated and validated in different ecosystems. The first four models generally provided better estimates than MOD17/MOD_ALG, which indicates that they have potential to capture the physical process of GPP variations in China. Different models resulted in different GPP estimations. As far as the TG model is concerned, $\mathrm{R}^{2}$ ranged from 0.34 in EBF to 0.93 in MF; RMSE varied from $30.37 \%$ in MF to $55.72 \%$ in grasslands. The model performances have been compared at five land cover types and VPM may be the most suitable model for GPP estimation in China, with $\mathrm{R}^{2}$ ranging from 0.34 in EBF to 0.90 in grasslands.

Different statistic indices for the five land cover types show that there are shifts of importance among various factors that determine the GPP variations. The impacts of EVI, PAR, LST, air temperature, and LSWI on photosynthesis have been further investigated for improving the model accuracies; for example, there is a good correlation between EVI and GPP for croplands, grasslands, and MF ( $\mathrm{r}=0.82,0.91$, and 0.95 , respectively), while $\mathrm{r}$ values were only 0.41 and $0.55(\mathrm{P}<0.01)$, respectively, for EBF and ENF. Thus, environmental factors (PAR, temperature, and water stress) should be considered carefully for GPP estimations in different ecosystems. Further research is needed to improve the model accuracy by studying the interactions between ecosystem and climatic variables. Spatial and temporal variations of GPP at the national scale will also be investigated in future.

\section{Acknowledgments}

We are grateful to the availability of the tower flux data from ChinaFLUX. We sincerely appreciate the editor and three anonymous reviewers for their constructive comments and suggestions. This work was supported by the National Natural Science Foundation of China (41371409 and 41127901). 


\section{Author Contributions}

Zhengjia Liu and Sisi Wang conducted and analyzed data. Zhengjia Liu and Lunche Wang wrote the manuscript. Zhengjia Liu, Lunche Wang, and Sisi Wang corrected and modified the manuscript.

\section{Conflicts of Interest}

The authors declare no conflict of interest.

\section{References}

1. Monteith, J.L. Solar radiation and productivity in tropical ecosystems. J. Appl. Ecol. 1972, 9, 747-766.

2. Beer, C.; Reichstein, M.; Tomelleri, E.; Ciais, P.; Jung, M.; Carvalhais, N.; Rödenbeck, C.; Arain, M.A.; Baldocchi, D.; Bonan, G.B. Terrestrial gross carbon dioxide uptake: Global distribution and covariation with climate. Science 2010, 329, 834-838.

3. Thanyapraneedkul, J.; Muramatsu, K.; Daigo, M.; Furumi, S.; Soyama, N.; Nasahara, K.; Muraoka, H.; Noda, H.; Nagai, S.; Maeda, T.; et al. A vegetation index to estimate terrestrial gross primary production capacity for the global change observation Mission-Climate (GCOM-C)/Second-Generation Global Imager (SGLI) satellite sensor. Remote Sens. 2012, 4, 3689-3720.

4. Yu, G.; Wen, X.; Sun, X.; Tanner, B.D.; Lee, X.; Chen, J. Overview of ChinaFLUX and evaluation of its eddy covariance measurement. Agric. For. Meteorol. 2006, 137, 125-137.

5. Gao, Y.; Yu, G.; Yan, H.; Zhu, X.; Li, S.; Wang, Q.; Zhang, J.; Wang, Y.; Li, Y.; Zhao, L. A MODIS-based Photosynthetic Capacity Model to estimate gross primary production in Northern China and the Tibetan Plateau. Remote Sens. Environ. 2014, 148, 108-118.

6. Zhao, M.; Running, S.W.; Nemani, R.R. Sensitivity of Moderate Resolution Imaging Spectroradiometer (MODIS) terrestrial primary production to the accuracy of meteorological reanalyses. J. Geophys. Res. 2006, 111, G01002.

7. Xiao, X.; Zhang, Q.; Braswell, B.; Urbanski, S.; Boles, S.; Wofsy, S.; Moore, B., III; Ojima, D. Modeling gross primary production of temperate deciduous broadleaf forest using satellite images and climate data. Remote Sens. Environ. 2004, 91, 256-270.

8. Sims, D.; Rahman, A.; Cordova, V.; Elmasri, B.; Baldocchi, D.; Bolstad, P.; Flanagan, L.; Goldstein, A.; Hollinger, D.; Misson, L. A new model of gross primary productivity for North American ecosystems based solely on the enhanced vegetation index and land surface temperature from MODIS. Remote Sens. Environ. 2008, 112, 1633-1646.

9. Coops, N.C.; Waring, R.H.; Law, B.E. Assessing the past and future distribution and productivity of ponderosa pine in the Pacific Northwest using a process model, 3-PG. Ecol. Model. 2005, 183, 107-124.

10. Yuan, W.; Liu, S.; Zhou, G.; Zhou, G.; Tieszen, L.L.; Baldocchi, D.; Bernhofer, C.; Gholz, H.; Goldstein, A.H.; Goulden, M.L.; et al. Deriving a light use efficiency model from eddy covariance flux data for predicting daily gross primary production across biomes. Agric. For. Meteorol. 2007, 143, 189-207. 
11. Wu, C.; Munger, J.W.; Niu, Z.; Kuang, D. Comparison of multiple models for estimating gross primary production using MODIS and eddy covariance data in Harvard Forest. Remote Sens. Environ. 2010, 114, 2925-2939.

12. Li, F.; Wang, X.; Zhao, J.; Zhang, X.; Zhao, Q. A method for estimating the gross primary production of alpine meadows using MODIS and climate data in China. Int. J. Remote Sens. 2013, $34,8280-8300$.

13. Gitelson, A.A.; Viña, A.; Verma, S.B.; Rundquist, D.C.; Arkebauer, T.J.; Keydan, G.; Leavitt, B.; Ciganda, V.; Burba, G.G.; Suyker, A.E. Relationship between gross primary production and chlorophyll content in crops: Implications for the synoptic monitoring of vegetation productivity. J. Geophys. Res. 2006, 111, D08S11.

14. Gitelson, A.A.; Peng, Y.; Masek, J.G.; Rundquist, D.C.; Verma, S.; Suyker, A.; Baker, J.M.; Hatfield, J.L.; Meyers, T. Remote estimation of crop gross primary production with Landsat data. Remote Sens. Environ. 2012, 121, 404-414.

15. Li, Z.; Yu, G.; Xiao, X.; Li, Y.; Zhao, X.; Ren, C.; Zhang, L.; Fu, Y. Modeling gross primary production of alpine ecosystems in the Tibetan Plateau using MODIS images and climate data. Remote Sens. Environ. 2007, 107, 510-519.

16. Yu, G.R.; Zhu, X.J.; Fu, Y.L.; He, H.L.; Wang, Q.F.; Wen, X.F.; Li, X.R.; Zhang, L.M.; Zhang, L.; Su, W. Spatial patterns and climate drivers of carbon fluxes in terrestrial ecosystems of China. Glob. Change Biol. 2013, 19, 798-810.

17. Zhao, M.; Heinsch, F.A.; Nemani, R.R.; Running, S.W. Improvements of the MODIS terrestrial gross and net primary production global data set. Remote Sens. Environ. 2005, 95, 164-176.

18. Jin, C.; Xiao, X.; Merbold, L.; Arneth, A.; Veenendaal, E.; Kutsch, W.L. Phenology and gross primary production of two dominant savanna woodland ecosystems in Southern Africa. Remote Sens. Environ. 2013, 135, 189-201.

19. Xiao, X.; Boles, S.; Liu, J.; Zhuang, D.; Liu, M. Characterization of forest types in Northeastern China, using multi-temporal SPOT-4 VEGETATION sensor data. Remote Sens. Environ. 2002, 82, 335-348.

20. Huete, A.R.; Liu, H.Q.; Batchily, K.; van Leeuwen, W. A comparison of vegetation indices over a global set of TM images for EOS-MODIS. Remote Sens. Environ. 1997, 59, 440-451.

21. Savitzky, A.; Golay, M.J. Smoothing and differentiation of data by simplified least squares procedures. Anal. Chem. 1964, 36, 1627-1639.

22. Sims, D.A.; Rahman, A.F.; Cordova, V.D.; El-Masri, B.Z.; Baldocchi, D.D.; Flanagan, L.B.; Goldstein, A.H.; Hollinger, D.Y.; Misson, L.; Monson, R.K.; et al. On the use of MODIS EVI to assess gross primary productivity of North American ecosystems. J. Geophys. Res. 2006, 111, G04015.

23. Fu, D.; Chen, B.; Zhang, H.; Wang, J.; Black, T.A.; Amiro, B.D.; Bohrer, G.; Bolstad, P.; Coulter, R.; Rahman, A.F.; et al. Estimating landscape net ecosystem exchange at high spatial-temporal resolution based on Landsat data, an improved upscaling model framework, and eddy covariance flux measurements. Remote Sens. Environ. 2014, 141, 90-104.

24. Wu, C.; Chen, J.M.; Huang, N. Predicting gross primary production from the enhanced vegetation index and photosynthetically active radiation: Evaluation and calibration. Remote Sens. Environ. 2011, 115, 3424-3435. 
25. Liu, Z.; Liu, J.; Shao, Q. Optimum temperature of vegetation growth for various land cover types in China. J. Geoinf. Sci. 2014, 16, 1-7.

26. Gebremichael, M.; Barros, A.P. Evaluation of MODIS gross primary productivity (GPP) in tropical monsoon regions. Remote Sens. Environ. 2006, 100, 150-166.

27. Yang, Y.; Shang, S.; Guan, H.; Jiang, L. A novel algorithm to assess gross primary production for terrestrial ecosystems from MODIS imagery. J. Geophys. Res. 2013, 118, 590-605.

28. Nagai, S.; Saigusa, N.; Muraoka, H.; Nasahara, K. What makes the satellite-based EVI-GPP relationship unclear in a deciduous broad-leaved forest? Ecol. Res. 2010, 25, 359-365.

29. Nagai, S.; Saitoh, T.M.; Kobayashi, H.; Ishihara, M.; Suzuki, R.; Motohka, T.; Nasahara, K.N.; Muraoka, H. In situ examination of the relationship between various vegetation indices and canopy phenology in an evergreen coniferous forest, Japan. Int. J. Remote Sens. 2012, 33, 6202-6214.

30. Running, S.W.; Nemani, R.R.; Heinsch, F.A.; Zhao, M.; Reeves, M.; Hashimoto, H. A continuous satellite-derived measure of global terrestrial primary production. Bioscience 2004, 54, 547-560.

31. Turner, D.P.; Ritts, W.D.; Cohen, W.B.; Gower, S.T.; Zhao, M.; Running, S.W.; Wofsy, S.C.; Urbanski, S.; Dunn, A.L.; Munger, J. Scaling gross primary production (GPP) over boreal and deciduous forest landscapes in support of MODIS GPP product validation. Remote Sens. Environ. 2003, 88, 256-270.

32. Wang, J.; Dong, J.; Liu, J.; Huang, M.; Li, G.; Running, S.; Smith, W.; Harris, W.; Saigusa, N.; Kondo, H.; et al. Comparison of gross primary productivity derived from GIMMS NDVI3g, GIMMS, and MODIS in Southeast Asia. Remote Sens. 2014, 6, 2108-2133.

33. Zhu, Z.; Bi, J.; Pan, Y.; Ganguly, S.; Anav, A.; Xu, L.; Samanta, A.; Piao, S.; Nemani, R.R.; Myneni, R.B. Global data sets of vegetation leaf area index (LAI) $3 \mathrm{~g}$ and Fraction of Photosynthetically Active Radiation (FPAR) 3g derived from Global Inventory Modeling and Mapping Studies (GIMMS) Normalized Difference Vegetation Index (NDVI3g) for the period 1981 to 2011. Remote Sens. 2013, 5, 927-948.

34. Hashimoto, H.; Wang, W.; Milesi, C.; White, M.A.; Ganguly, S.; Gamo, M.; Hirata, R.; Myneni, R.B.; Nemani, R.R. Exploring simple algorithms for estimating gross primary production in forested areas from satellite data. Remote Sens. 2012, 4, 303-326.

35. Huete, A.; Didan, K.; Miura, T.; Rodriguez, E.P.; Gao, X.; Ferreira, L.G. Overview of the radiometric and biophysical performance of the MODIS vegetation indices. Remote Sens. Environ. 2002, 83, 195-213.

36. Mu, Q.; Zhao, M.; Running, S.W. Improvements to a MODIS global terrestrial evapotranspiration algorithm. Remote Sens. Environ. 2011, 115, 1781-1800.

(C) 2014 by the authors; licensee MDPI, Basel, Switzerland. This article is an open access article distributed under the terms and conditions of the Creative Commons Attribution license (http://creativecommons.org/licenses/by/4.0/). 